\title{
BMJ
}

\section{Effect of the quality and outcomes framework on diabetes care in the United Kingdom: retrospective cohort study}

\author{
Melanie Calvert, senior lecturer, ${ }^{1}$ Aparna Shankar, research fellow, ${ }^{2}$ Richard I McManus, clinical senior \\ lecturer, ${ }^{1}$ Helen Lester, professor of primary care, ${ }^{3}$ Nick Freemantle, professor of clinical epidemiology and \\ biostatistics ${ }^{1}$
}

'Department of Primary Care and General Practice, University of

Birmingham, Edgbaston,

Birmingham B15 2TT

${ }^{2}$ Department of Epidemiology and Public Health, University College London

${ }^{3}$ National Primary Care Research and Development Centre University of Manchester Correspondence to: $M$ Calvert m.calvert@bham.ac.uk

Cite this as: BMJ 2009;338:b1870 doi:10.1136/bmi.b1870

\section{ABSTRACT}

Objectives To examine the management of diabetes between 2001 and 2007 in the United Kingdom and to assess whether changes in the quality of care reflect existing temporal trends or are a direct result of the implementation of the quality and outcomes framework. Design Retrospective cohort study.

Setting 147 general practices (annual list size over 1 million) across the UK.

Patients People with type 1 or type 2 diabetes.

Main outcome measures Annual prevalence of diabetes and attainment of process and clinical outcomes over the three years before and the three years after the introduction of the quality and outcomes framework. Results Significant improvements in process and intermediate outcome measures were observed during the six year period, with consecutive annual improvements observed before the introduction of incentives. However, the current diagnostic case definition for the quality and outcomes framework does not capture up to two thirds of people with type 1 diabetes and a third of people with type 2 diabetes. After the introduction of the quality and outcomes framework, existing trends of improvement in glycaemic control, cholesterol levels, and blood pressure were attenuated, particularly in people with diabetes who did not meet the case definition of the quality and outcomes framework. The introduction of the quality and outcomes framework did not lead to improvement in the management of patients with type 1 diabetes, nor to a reduction in the number of patients with type 2 diabetes who had $\mathrm{HbA}_{1 \mathrm{c}}$ levels greater than $10 \%$. Introduction of the quality and outcomes framework may have increased the number of patients with type 2 diabetes with $\mathrm{HbA}_{1 \mathrm{c}}$ levels of $\leq 7.5 \%$; odds ratio 1.05 (95\% confidence interval 1.01 to 1.09 ; $\mathrm{P}=0.02$ ).

Conclusions The management of people with diabetes has improved since the late 1990s, but the impact of the quality and outcomes framework on care is not straightforward; upper thresholds may need to be removed or targets made more challenging if people are to benefit. Many patients in whom care may be suboptimal may not be captured in the quality and outcomes framework assessment.

\section{INTRODUCTION}

Performance based payment incentives are now a routine part of many health economies. ${ }^{1}$ In April 2004 the quality and outcomes framework was first introduced as part of the general practitioner contract in the United Kingdom. ${ }^{2}$ This scheme offers financial rewards for achieving a series of process outcome measures (what is actually done in giving and receiving care) and intermediate outcome measures (changes in health status that affect subsequent health outcomes) that should improve the quality of patient care. The quality and outcomes framework comprises a range of criteria grouped into four domains: clinical, organisational, patient experience, and additional services. ${ }^{3}$ For the period 2006-7 a total of 80 indicators were included in the clinical domain, with a maximum of 655 points achievable from an overall total of 1000 points. Indicators for diabetes account for 93 of these points, the largest single clinical area, and cover 18 separate indicators covering structure (maintaining a register of patients with diabetes), process (measurement), and intermediate outcomes such as blood pressure, cholesterol level, and glycaemic $\left(\mathrm{HbA}_{1 \mathrm{c}}\right.$ level) control. Payments are staged, and to be eligible for maximum payment practices are required to achieve a minimum target before they are paid - that is, the lower threshold and a maximum or upper threshold. ${ }^{4}$ Maximum thresholds for most clinical process indicators in diabetes are currently set at $90 \%$ but are lower for intermediate outcome indicators. Thus the upper threshold for the proportion of people with $\mathrm{HbA}_{1 \mathrm{c}}$ levels of 7.5\% or less is $50 \%$, for a blood pressure reading of 145 / $85 \mathrm{~mm} \mathrm{Hg}$ or less is $60 \%$, and for a cholesterol level of $5 \mathrm{mmol} / 1$ or less is $70 \%{ }^{4}$ When a general practitioner (or the patient) judges that treatment to these targets is inappropriate-for example, terminal disease or patient choice - a patient may be "excepted" from the indicator denominator. ${ }^{3}$ Within the diabetes domain the median exception reporting rate is $5.4 \%$. $^{5}$

Data on people with diabetes are identified for analysis in the quality and outcomes framework using primary care morbidity codes (Read codes). Read codes are a hierarchical coding system used to code clinical data, including signs, symptoms, procedures, 
investigations, and diagnoses. ${ }^{6}$ The current version of Read codes are five characters long, with the first character indicating the disease area and later characters providing more precise detail. ${ }^{7}$ When the quality and outcomes framework was first introduced, people with diabetes were identified on the basis of the presence of any diabetes Read code $(\mathrm{C} 10$ and any codes below it in the hierarchy). In April 2006 the case definition for diabetes was changed to a narrower set of more specific Read codes; identifying type 1 diabetes mellitus (the $\mathrm{C} 10 \mathrm{E}$ hierarchy: $\mathrm{C} 10 \mathrm{E} 0$ to $\mathrm{C} 10 \mathrm{EP}$ ) and identifying type 2 diabetes mellitus (the $\mathrm{C} 10 \mathrm{~F}$ hierarchy: $\mathrm{C} 10 \mathrm{~F} 0$ to $\mathrm{C} 10 \mathrm{FQ}){ }^{8}$ Studies have shown that prevalence is underestimated if only these specific $\mathrm{C} 10 \mathrm{E}$ and $\mathrm{C} 10 \mathrm{~F}$ Read codes are used, and interpretation of the change in the quality and outcomes framework indicators has proved difficult because of this change in case definition. ${ }^{89}$ Furthermore, even the use of the less specific C10 Read codes may exclude some people with diabetes from evaluation through the quality and outcomes framework.

Since the introduction of the quality and outcomes framework a series of studies has suggested an improvement in the management of people with diabetes in primary care..$^{9-12}$ Notably, one study suggested "that the introduction of pay for performance was associated with a modest acceleration in improvement" in the management of diabetes. ${ }^{10}$ However, this work assessed care at only three time points, one of which followed the introduction of the quality and outcomes framework and was based on relatively small numbers of selected patients and therefore may not be fully representative of care. Other studies have focused on specific regions in the UK and may not be generalisable. ${ }^{112}$ It therefore remains unclear to what extent the introduction of incentives has impacted on existing temporal trends, reflecting, for example, the national quality improvement strategy. ${ }^{10}$

We examined the prevalence of diabetes and the proportion of people meeting targets for diabetes management annually from April 2002 to March 2007 (three years before and three years after the introduction of the quality and outcomes framework). We also assessed the impact of the quality and outcomes framework on clinical outcomes (glycaemic control, cholesterol levels, and blood pressure) in people with type 1 and type 2 diabetes.

\section{METHODS}

We obtained data from the doctors' independent network (DIN)-LINK database, which contains anonymised computer records from primary care practices in the UK using iSOFT (previously TOREX) clinical systems including morbidity coding, biochemical test results, prescribing data, and ACORN geodemographic classification (a classification of residential neighbourhoods - a deprivation score)..$^{1314}$ The age-sex structure of the DIN-LINK database has been shown to be similar to the UK average, but practices in the south of England and higher socioeconomic groups are over-represented. ${ }^{15} \mathrm{We}$ identified people with a diagnosis of diabetes from practices with continuous data over a 10 year period, from 1 April 1997 to 31 March 2007. Analyses were done using SAS V9.1.

\section{Identification of people with diabetes}

We identified people with diabetes if they had a Read code for diabetes or one or more prescriptions for oral antidiabetic drugs, insulin, or glucose testing kits. MJC and AS identified relevant Read codes, which were verified by a clinician (RJM). Read codes included those in the $\mathrm{C} 10$ hierarchy and other diabetes related Read codes including diabetes monitoring, referrals, and diabetes related eye and foot complications. We excluded women with gestational diabetes unrelated to pre-existing diabetes. People were classified as having type 1 diabetes if they were prescribed insulin (or an insulin device), did not have a Read code for type 2 diabetes, or had any previous prescription for an oral antidiabetic drug. The remaining people were classified as having type 2 diabetes.

In addition, in order to be able to interpret the effect of the change in diagnostic case definition in the quality and outcomes framework which occurred from April 2006, we also identified the first occurrence of Read codes in the $\mathrm{C} 10 \mathrm{E}$ (type 1 diabetes mellitus) or $\mathrm{C} 10 \mathrm{~F}$ (type 2 diabetes mellitus) hierarchies for people during the study period. ${ }^{8}$

\section{Prevalence of diabetes}

The prevalence of diabetes was estimated annually on the 31 March from 2002-7. We considered all people with a diagnosis of diabetes who were registered in each practice on each date.

Attainment of targets in quality and outcomes framework We carried out analyses on attainment of diabetes and smoking outcomes using data between 1 January 2001 and 31 March 2007, as annual targets in the quality and outcomes framework are assessed over a 15 month period (Department of Health business rules). ${ }^{16}$ These definitions were adhered to with the following exceptions: for our principal analyses we considered all people with diabetes (rather than only those with clinical Read codes). In the primary analyses we excluded diabetes exception reporting codes $(9 \mathrm{~h} 4 \mathrm{hier}-$ archy) that did not give the reason for exception. We did, however, include outcome specific exception codes such as contraindication codes and maximal therapy codes. We undertook a series of sensitivity analyses to assess attainment of outcomes in people with recorded Read codes in the $\mathrm{C} 10 \mathrm{E}$ and $\mathrm{C} 10 \mathrm{~F}$ hierarchies and the impact of diabetes exception reporting (9h4 codes) on glycaemic control.

Impact of quality and outcomes framework on glycaemic control

We assessed the relation between attainment of glycaemic targets $\left(\mathrm{HbA}_{1 \mathrm{c}}\right.$ levels $\leq 7.5 \%$ and $\left.\leq 10 \%\right)$ and year of assessment, the introduction of the quality and 
outcomes framework, and evidence of the new diagnostic coding definitions, using mixed models with a logit link and binomial error and a random effect term describing the effect of practice with a Gaussian error structure using the SAS nlmixed procedure (SAS V9. 1). Four separate models were produced: response variable $\mathrm{HbA}_{1 \mathrm{c}}$ level $\leq 7.5 \%$ in people with type 1 diabetes; response variable $\mathrm{HbA}_{1 \mathrm{c}}$ level $\leq 10 \%$ in people with type 1 diabetes; response variable $\mathrm{HbA}_{1 \mathrm{c}}$ level $\leq 7.5 \%$ in people with type 2 diabetes; response variable $\mathrm{HbA}_{1 \mathrm{c}}$ level $\leq 10 \%$ in people with type 2 diabetes. For patients with multiple assessments of $\mathrm{HbA}_{1 \mathrm{c}}$ levels recorded during each year we used the latest assessment before the quality and outcomes framework reference date. We assessed linear and non-linear functional forms (natural logarithm and exponential functions) for year. To allow for a sudden shift in the rate of change as a result of the introduction of the quality and outcomes framework in addition to annual changes we used an additional variable to indicate whether the quality and outcomes framework was being implemented. The presence of the new quality and outcomes framework diagnostic coding (C10E or $\mathrm{C} 10 \mathrm{~F}$ hierarchies) were also coded variables to assess the impact of being included in the pay for performance review on glycaemic control. Interaction terms were assessed. We derived the denominator degrees of freedom from the number of practices. Akaike's information criterion was used to determine the best model fit and most appropriate functional form for annual changes. ${ }^{17}$

\section{RESULTS}

Overall, 147 of the 300 practices contributing to the DIN-LINK database had usable data over the study period, of which $34(23 \%)$ provided pharmacy dispensing services in addition to primary medical care. The practices employed a mean number of 5.8 general practitioners (SD 2.9) and on 31 March 2007 had a mean list size of 8929 (SD 4147).

\section{Prevalence of diabetes}

During the six years of the study period (2002-7) the recorded prevalence of type 1 diabetes remained stable whereas the recorded prevalence of type 2 diabetes increased (fig 1). The use of specific morbidity codes for type 1 and type 2 diabetes increased over time but remained about two thirds of the total codes for diabetes at the end of the study period.

\section{Changes in quality and outcomes framework indicators over time}

Improvements in all diabetes indicators were observed over the study period (tables 1 and 2 and fig 2). The proportion of people with type 1 diabetes attaining process targets was greater than $70 \%$ in 2007 , with the exception of testing for microalbuminuria. The proportion of people with type 2 diabetes attaining these targets was higher.

The proportion of people attaining intermediate outcomes also improved over time but was lower than that observed for process targets. The proportion of people with type 1 and type 2 diabetes attaining targets for glycaemic control $\left(\mathrm{HbA}_{1 \mathrm{c}}\right.$ level $\leq 7.5 \%$ and $\left.\leq 10 \%\right)$, cholesterol level, and blood pressure showed attenuation of annual trends in improvement after the introduction of the quality and outcomes framework (fig 2). This effect appeared greater for the proportion of people attaining glycaemic control.

Model results (table 3) showed significant annual increases in the proportion of people attaining targets for $\mathrm{HbA}_{1 \mathrm{c}}$ levels. Target attainment was significantly higher in those people with a quality and outcomes framework diagnostic Read code (with the exception of people with type 1 diabetes and $\mathrm{HbA}_{1 \mathrm{c}}$ target $\leq 10 \%$ ). Introduction of the quality and outcomes framework was only significantly associated with an increase in the proportion of people attaining $\mathrm{HbA}_{1 \mathrm{c}}$ target $\leq 7.5 \%$ in people with type 2 diabetes, and this effect was relatively small.

\section{Characterisation of people without quality and outcomes framework case definition Read codes}

In light of the findings, the use of the quality and outcomes framework diagnostic Read codes was examined in the most recent (2007) cohort. A total of 3811 people with type 1 diabetes were in the 2007 cohort for $\mathrm{HbA}_{1 \mathrm{c}}$ levels, of whom 1228 had a specific $\mathrm{C} 10 \mathrm{E}$ code and would be assessed in the quality and outcomes framework. Of the remaining 2583 people, none had a
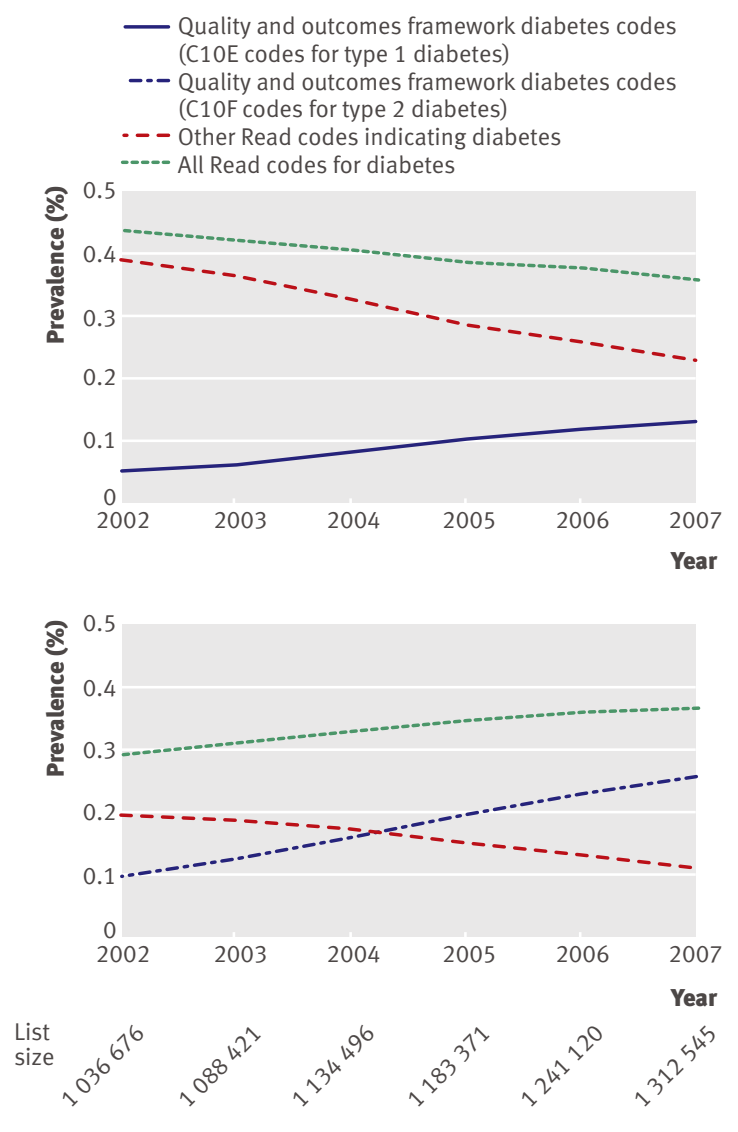

Fig 1| Prevalence of type 1 and type 2 diabetes across study period 
Read code indicating type 2 diabetes and all had a prescription for insulin but no oral antidiabetic drug before the quality and outcomes framework reference date. Exploratory analyses indicated that people with a $\mathrm{C} 10 \mathrm{E}$ hierarchy Read code were younger than those without a C10E code (mean ages 40.6 v 50.4 years; $\mathrm{P}<0.001)$. They were also more likely to be men (61.4\% v 55.3\%, $\mathrm{P}<0.001)$.

A total of 42032 people with type 2 diabetes in the 2007 cohort for $\mathrm{HbA}_{1 \mathrm{c}}$ levels were identified, of whom 29674 had a specific C10F hierarchy Read code. Of the remaining 12358 people without a $\mathrm{C} 10 \mathrm{~F}$ code,
$8994(72.8 \%)$ had either a prescription for an oral agent and insulin or insulin device before the reference date or a Read code indicating diabetic treatment. Overall, 2460 people (19.9\%) had either the broader diabetes Read codes (C10 hierarchy) or the Read codes indicating screening for, or complications associated with, diabetes, such as eye and foot complications. Of the remaining people, 904 (7.3\%) had Read codes indicating assessment or care of diabetes. People with a $\mathrm{C} 10 \mathrm{~F}$ code were older than those without a $\mathrm{C} 10 \mathrm{~F}$ code (mean ages $66.1 v 63.5$ years; $\mathrm{P}<0.001$ ). They were also more likely to be men $(55.2 \%$ v
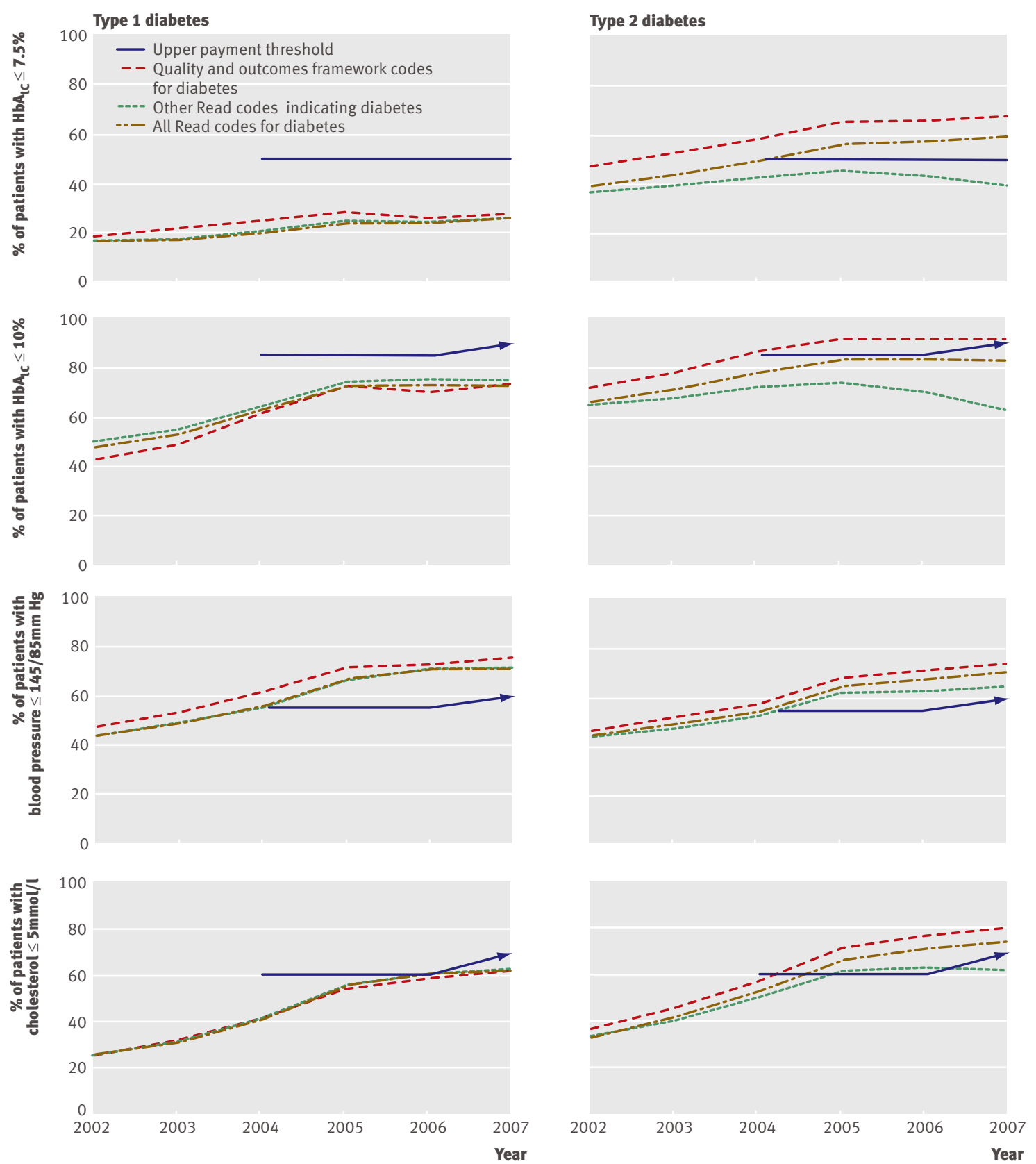

Fig 2 Proportion of patients with diabetes meeting quality and outcomes framework targets for $\mathrm{HbA}_{1 \mathrm{c}}$ level, cholesterol level, and blood pressure. For patients with multiple assessments during each period the last measurement during the year was used 
Table 1| Number (percentage) of people with type 1 diabetes meeting quality and outcomes framework targets in previous 15 months from 1 April $2002-7$ Variables 2002 2003 2004 2005 2006 2007

DM2 with record of body $1201 / 4028$ (29.8) 1448/4074 (35.5) $2143 / 4086(52.5)$ $3104 / 4042$ (76.8) $3301 / 4117$ (80.2) $3338 / 4146$ (80.5)

$2571 / 4028$ (63.8)

$2763 / 4074(67.8)$

$3197 / 4086(78.2)$

$3687 / 4042(91.2)$

$3737 / 4117(90.8)$

$3827 / 4146$ (92.3)

smoking status except

never smokers, when

smoking status should be

recorded once

DM4 smokers with record

$218 / 885$ (24.6)

$232 / 898(25.8)$

482/938 (51.4)

744/892 (83.4)

$764 / 929(82.3)$

$780 / 902(86.5)$

cessation has been offered

DM5 with record of $\mathrm{HbA}_{1 \mathrm{c}}$ or

equivalent

$\mathrm{DM} 5$ with record of $\mathrm{HbA}_{1 \mathrm{c}}$ O

$2337 / 4028$ (58.0)

$2589 / 4074$ (63.6)

$3050 / 4086(74.7)$

$3433 / 4042(84.9)$

$3534 / 4117$ (85.8)

$3540 / 4146(85.4)$

equivale

$2337 / 4028(58.0)$

2589/4074 (63.6)

$3036 / 4068(74.6)$

$3249 / 3732(87.1)$

$3168 / 3607$ (87.8)

$3220 / 3661(88.0)$

exception reporting)

DM20 with last recorded

$\mathrm{HbA}_{1 \mathrm{c}}$ (or equivalent) level

$613 / 3799(16.1)$

$657 / 3858$ (17.0)

$793 / 3873(20.5)$

$907 / 3639$ (24.9)

$912 / 3723(24.5)$

$1003 / 3811$ (26.3)

of $\leq 7.5 \%$ *

DM20 with $\mathrm{C} 10 \mathrm{E}$ codes and

last recorded $\mathrm{HbA}_{1 \mathrm{c}}$ (or

$53 / 289(18.3)$

$83 / 394(21.1)$

$146 / 587(24.9)$

$221 / 782$ (28.3)

262/1013 (25.9)

$349 / 1228(28.4)$

equivalent) level of $\leq 7.5 \%$ *

DM7 with last recorded

$\mathrm{HbA}_{1 \mathrm{c}}$ (or equivalent) level

1861/3799 (49.0)

$2076 / 3858$ (53.8)

$2462 / 3873(63.6)$

$2658 / 3639(73.0)$

$2737 / 3723$ (73.5)

2805/3811 (73.6)

of $\leq 10 \%$

DM7 with $\mathrm{C} 10 \mathrm{E}$ codes and

$123 / 289$ (42.6)

192/394 (48.7)

$364 / 587$ (62.0)

$577 / 782(73.8)$

$712 / 1013(70.3)$

$901 / 1228(73.4)$

last recorded $\mathrm{HbA}_{1 \mathrm{c}}$ (o

equivalent) level of $\leq 10$

DM21 with record of retinal

screening $†$

DM9 with record of

presence or absence of

peripheral pulses

DM10 with record of

neuropathy testing

$113 / 4028(27.6)$

$1350 / 4074(33.1)$

$2150 / 4086(52.6)$

2939/4026 (73.0)

$3038 / 4062(74.8)$

$3186 / 4015$ (79.4)

DM11 with record of blood pressure reading

DM12 with last recorded

blood pressure of $\leq 145$ /

$339 / 4028(8.4)$

461/4074 (11.3)

$1150 / 4084$ (28.2)

2726/4024 (67.7)

2986/4082 (73.2)

$2955 / 4100(72.1)$

$85 \mathrm{~mm} \mathrm{Hg}$

DM13 with record of microalbuminuria testing

DM22 with record of

estimated glomerular

filtration rate or serum

creatinine testing $\ddagger$

DM15 with diagnosis of

$207 / 4028$ (5.1)

318/4074 (7.8)

$1002 / 4084$ (24.5)

$2677 / 4024(66.5)$

$2967 / 4082(72.7)$

$2945 / 4100(71.8)$

proteinuria or

$2763 / 4028(68.6)$

$3013 / 4074$ (74.0)

$3285 / 4086(80.4)$

$3644 / 4042$ (90.2)

$3721 / 4117$ (90.4)

$3759 / 4143$ (90.7)

microalbuminuria and

treated with ACE inhibitors

(or A2 antagonists)

DM16 with record of

cholesterol level

$1684 / 3799$ (44.3)

$1921 / 3858$ (49.8)

2173/3887 (55.9)

$2558 / 3794$ (67.4)

$2726 / 3850$ (70.8)

$2810 / 3893(72.2)$

440/3934 (11.2)

$600 / 3979(15.1)$

$1053 / 3978$ (26.5)

$2202 / 3878$ (56.8)

$2450 / 3929(62.4)$

$2553 / 3955$ (64.6)

$1839 / 4028$ (45.7)

2103/4074 (51.6)

$2595 / 4086$ (63.5)

$3208 / 4042(79.4)$

$3386 / 4117$ (82.2)

$3433 / 4146(82.8)$

DM17 with last measured

80/108 (74.1)

$80 / 113(70.8)$

94/136 (69.1)

$186 / 245$ (75.9)

$224 / 286(78.3)$

$248 / 305$ (81.3)

cholesterol level of

$\leq 5 \mathrm{mmol} / \mathrm{l}$

DM18 vaccinated agains

influenza in preceding 1

September to 31 March

DM identifies specific quality and outcomes framework diabetes indicator.

$\mathrm{ACE}=$ angiotensin converting enzyme.

*Formerly DM6 and used $\mathrm{HbA}_{1 \mathrm{c}}$ target of $7.4 \%$.

†Formerly DM8 and changed as practices need to show that patients have received screening.

fFormerly DM14 and included record of only serum creatinine level. 
$51.8 \%, \mathrm{P}<0.001)$ and to belong to a higher socioeconomic class $(66.8 \%$ v $58.3 \% ; \mathrm{P}<0.001)$.

\section{DISCUSSION}

Significant improvements were seen in all of the quality and outcomes framework clinical indicators over time for diabetes care in the UK. The results also highlight differences in the management of people with type 1 and type 2 diabetes, as those with type 2 diabetes generally underwent more testing for diabetes related complications than people with type 1 diabetes. This might reflect the fact that a higher proportion of people with type 1 diabetes receive specialist care that may not be as well recorded in primary care records. ${ }^{18}$ By the end of the study in 2007, attainment of process measures was high. Whether this was a direct result of the quality and outcomes framework or reflects existing trends in improvement of care over time in response to clinical evidence, national guidelines, and other driving factors remains unclear. ${ }^{10}$

Significant improvements in clinical intermediate outcome measures (glycaemic control, cholesterol level, and blood pressure) were observed over the study period, with successive improvements being observed before the introduction of the quality and outcomes framework. This could in part be due to awareness among general practitioners of its impending introduction or the influence of national service frameworks in England and Wales and other clinical governance initiatives. After the introduction of the quality and outcomes framework, the trends appear to be attenuated. One study observed a modest acceleration in the improvement of care between 2003 and 2005 compared with 1998 to 2003, which the authors suggested might have been associated with the introduction of pay for performance. ${ }^{10}$ In our study, outcomes appeared to improve consistently between 2002 and 2005, with attenuation in observed improvement between 2005 and 2007. This attenuation could reflect the increasing difficulty of target attainment in poorly controlled people because even in conditions of a clinical trial some people are unable to attain long term control. ${ }^{19}$ However the attenuation of temporal trends might also reflect the lack of further incentive after attainment of the upper payment thresholds (the ceiling effect). This could suggest that upper thresholds need to be removed or targets made more challenging in line with the evidence base rather than the current alignment with lower audit targets. Both the lower and the upper thresholds were, however, shifted upwards for several intermediate outcomes in 2006, which does not appear to be reflected in subsequent target attainment, suggesting that further changes would require careful evaluation. If the observed ceiling effect does represent the natural equilibrium of current optimal management in primary care, this highlights the remaining gap in treatment and the need for new therapies, improved education, or management strategies.

In 2007 the monitoring and control of glycaemia still seemed suboptimal in some people, with over $10 \%$ of people having no record of an $\mathrm{HbA}_{1 \mathrm{c}}$ level or equivalent in the previous 15 months. Twenty six per cent of people with type 1 diabetes and $17 \%$ with type 2 diabetes had an $\mathrm{HbA}_{1 \mathrm{c}}$ level of more than $10 \%$, and $41 \%$ of people with type 2 diabetes and $74 \%$ with type 1 diabetes had an $\mathrm{HbA}_{1 \mathrm{c}}$ level of more than $7.5 \%$. Similarly, nearly a third of patients had evidence of raised blood pressure and over a quarter of patients had raised serum cholesterol levels. The introduction of the quality and outcomes framework seems to be significantly associated with better glycaemic control in people with type 2 diabetes for the more stringent target $\left(\mathrm{HbA}_{1 \mathrm{c}}\right.$ level $\left.\leq 7.5 \%\right)$, although the quality and outcomes framework did not seem to significantly predict attainment of the higher target $\left(\mathrm{HbA}_{1 \mathrm{c}}\right.$ level $\leq 10 \%$ ), and attenuation in trends was observed for both targets. Since the maximum payment threshold for payment for an $\mathrm{HbA}_{1 \mathrm{c}}$ target of $7.5 \%$ or less is $50 \%$, the quality and outcomes framework seems to offer no further incentive for optimal glycaemic control for many people. However, since attainment was over $60 \%$ on average, perhaps greater thought is needed for additional targeting of poorly performing practices as opposed to general interventions or developing and implementing more nuanced indicators. It may be, for example, that introducing a system of tightly linked process measures into the diabetes domain, similar to the system used by the Veterans Administration, ${ }^{20}$ could improve care further, although this would require some modification to the information technology infrastructure underpinning the quality and outcomes framework.

We observed substantial variation in the level of glycaemic control attained across practices. For example, the median proportion of people with type 1 diabetes achieving the $\mathrm{HbA}_{1 \mathrm{c}}$ target of $7.5 \%$ or less in 2007 was $25.8 \%$ (interquartile range 20.0-32.5\%), with one practice reporting that all patients had $\mathrm{HbA}_{1 \mathrm{c}}$ levels less than or equal to $7.5 \%$ and for people with type 2 diabetes the median was $60.1 \%(55.4-65.5 \%)$, with 14 practices reporting that less than half of patients achieved the target and only three practices reporting that over three quarters of patients achieved the target. Characteristics of the patient population in each practice, including prevalence of disease, case mix, and list size have been shown to influence attainment of targets. $^{2122}$ Management may also be affected by the views of patients and healthcare providers. ${ }^{23}$

Subgroup analyses of attainment of intermediate outcomes (glycaemic control, cholesterol level, and blood pressure) by patients with or without a Read code meeting the quality and outcomes framework case definition $(\mathrm{C} 10 \mathrm{E}$ and $\mathrm{C} 10 \mathrm{~F})$ indicate that people included in the quality and outcomes framework denominator, and particularly those with type 2 diabetes, were in general more likely to attain the targets. Our finding that older people, men, and those from affluent backgrounds seem more likely to have a specific $\mathrm{C} 10 \mathrm{~F}$ hierarchy code and therefore be assessed within the quality and outcomes framework is consistent with others' work on the relation between patients' personal characteristics and attainment of targets, and 
Table 2 | Number (percentage) of people with type 2 diabetes meeting quality and outcomes framework targets in previous 15 months from 1 April $2002-7$

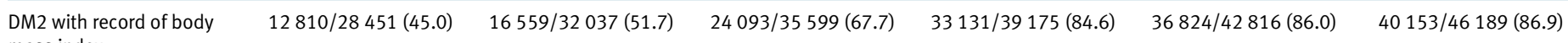

mass index

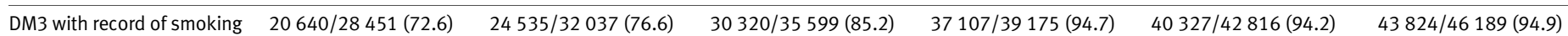

status except never

smokers, where smoking

status should be recorded

once

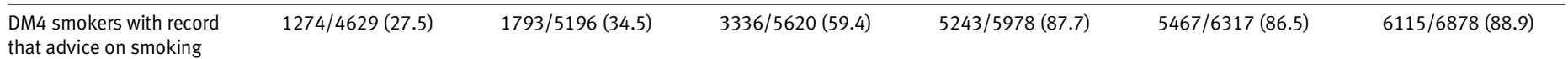

cessation has been offered

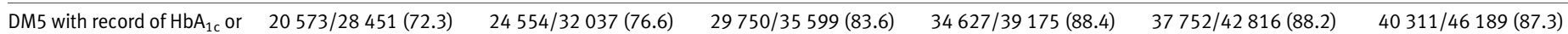

equivalent level

DM5 with record of $\mathrm{HbA}_{1 \mathrm{c}}$

level or equivalent (using

diabetes exception

reporting)

DM20 with last recorded

$\mathrm{HbA}_{1 \mathrm{c}}$ (or equivalent) level of

$\leq 7.5 \%$ *

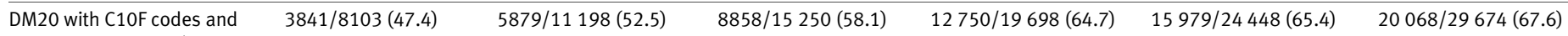

last recorded $\mathrm{HbA}_{1 \mathrm{c}}$ (or

equivalent) level of $\leq 7.5 \%$ *

DM7 with last recorded

$\mathrm{HbA}_{1 \mathrm{c}}$ (or equivalent) level of

$\leq 10 \%$

DM7 with C10F codes and

$20573 / 28451(72.3) \quad 24553 / 32035(76.6) \quad 29658 / 35465(83.6) \quad 33176 / 37197(89.2) \quad 35615 / 39906(89.3) \quad 38116 / 43172(88.3)$

last recorded $\mathrm{HbA}_{1 \mathrm{c}}$ (or

equivalent) level of $\leq 10 \%$

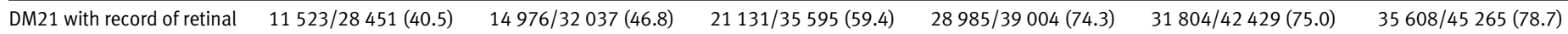

screening†

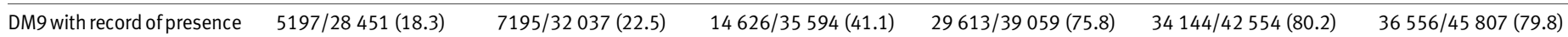

or absence of peripheral

pulsest

DM10 with record of

neuropathy testing

$17327 / 26082(66.4) \quad 20933 / 29413(71.2) \quad 25562 / 32658(78.3) \quad 29412 / 35271(83.4) \quad 32191 / 38621(83.4) \quad 34756 / 42032(82.7)$

$5779 / 8103(71.3)$

$8652 / 11198(77.3)$

$13074 / 15250(85.7)$

$17950 / 19698(91.1)$

$22332 / 24448(91.3) \quad 27090 / 29674(91.3)$

DM11 with record of blood

pressure reading

DM12 with last recorded

blood pressure of $\leq 145$

(3.

(34) 340

$85 \mathrm{~mm} \mathrm{Hg}$

\begin{tabular}{|c|c|c|c|c|c|c|}
\hline $\begin{array}{l}\text { DM13 with record of } \\
\text { microalbuminuria testing }\end{array}$ & $4186 / 28107$ (14.9) & $7447 / 31658(23.5)$ & $12715 / 35072(36.3)$ & $25686 / 38053(67.5)$ & $30540 / 41210(74.1)$ & 33 291/44 234 (75.3) \\
\hline DM22 with record of & $18053 / 28451$ (63.5) & $22225 / 32037$ (69.4) & $28374 / 35599(79.7)$ & 35 414/39 175 (90.4) & $39124 / 42816(91.4)$ & $42181 / 46189$ (91.3) \\
\hline
\end{tabular}

estimated glomerular

filtration rate or serum

creatinine testing $\ddagger$

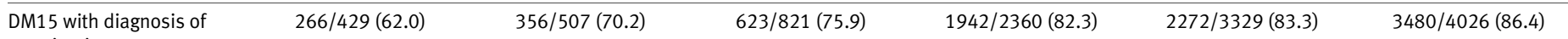

proteinuria or

microalbuminuria and

treated with ACE inhibitors

(or A2 antagonists)

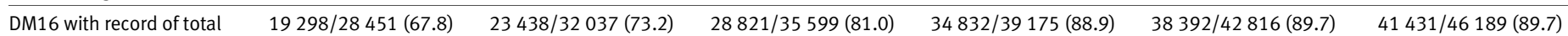

cholesterol level

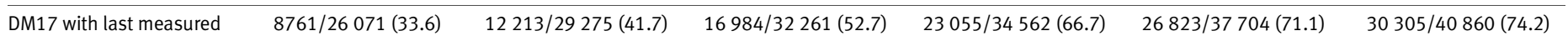

total cholesterol level of

$\leq 5 \mathrm{mmol} / \mathrm{l}$

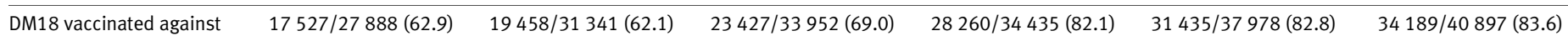

influenza in preceding 1

September to 31 March

DM identifies specific quality and outcomes framework diabetes indicator.

$\mathrm{ACE}=$ angiotensin converting enzyme.

*Formerly DM6 and used target $\mathrm{HbA}_{1 c}$ of $7.4 \%$.

†Formerly DM8 and changed as practices need to show that patients have received screening.

fFormerly DM14 and included record of only serum creatinine level. 
Table 3|Relation between glycaemic control with time, introduction of quality and outcomes framework, and meeting diagnostic case definition of quality and outcomes framework

\begin{tabular}{|c|c|c|c|c|}
\hline \multirow[b]{2}{*}{ Variables } & \multicolumn{2}{|c|}{$\mathrm{HbA}_{1 \mathrm{c}}$ target $\leq 7.5 \%$} & \multicolumn{2}{|c|}{$\mathrm{HbA}_{1 \mathrm{c}}$ target $\leq 10 \%$} \\
\hline & Odds ratio $(95 \% \mathrm{Cl})$ & $P$ value & Odds ratio $(95 \% \mathrm{Cl})$ & $P$ value \\
\hline \multicolumn{5}{|l|}{ Type 1 diabetes: } \\
\hline Year & $1.02(1.01$ to 1.04$) \dagger$ & 0.003 & 1.06 (1.03 to 1.08$)$ & $<0.001$ \\
\hline Quality and outcomes framework & * & * & * & * \\
\hline Presence of C10E Read code & 1.41 (1.24 to 1.59$)$ & $<0.001$ & 0.72 (0.64 to 0.80$)$ & $<0.001$ \\
\hline Year and presence of C10E Read code & $0.97(0.90$ to 1.0$) \dagger$ & 0.04 & * & * \\
\hline \multicolumn{5}{|l|}{ Type 2 diabetes: } \\
\hline Year & 1.06 (1.05 to 1.08$)$ & $<0.001$ & $+2.51(2.13$ to 2.95$)$ & 0.001 \\
\hline Quality and outcomes framework & 1.05 (1.01 to 1.09$)$ & 0.02 & * & * \\
\hline Presence of C10F Read code & 1.67 (1.64 to 1.71$)$ & $<0.001$ & 1.68 (1.61 to 1.75$)$ & $<0.001$ \\
\hline
\end{tabular}

Years were coded in model as -3 to 2 to indicate their relation to introduction of quality and outcomes framework unless otherwise stated.

*Variable not included in final model as non-significant (P>0.05).

†Year with an exponential transformation.

+Year with log transformation (rescaled years as 1 to 6). Although this rescaled log transformed model had best model fit as judged by Akaike's

information criterion, this metric is difficult to interpret practically.

raises concerns that the quality and outcomes framework may not have been as efficient in reducing inequalities in health in diabetes as was hoped. ${ }^{2224}$ Detailed assessment of Read codes and prescriptions for patients that did not meet the current case definition for the quality and outcomes framework indicates that an important group of people that seem to have diabetes are no longer included within the quality and outcomes framework. Some of these $(<7 \%)$ may purely have been included in the study definition on the basis of monitoring for suspected diabetes and therefore reasonably not received comprehensive diabetes care, which may contribute to the apparent reduced care in people not meeting the diagnostic case definition of the quality and outcomes framework. An alternative explanation for the apparent reduced level of care in people without $\mathrm{C} 10 \mathrm{~F}$ codes is the selective exclusion of poorly managed patients by clinicians that might lead to increased income. However such "gaming" was not seen on a wide scale in a recent evaluation of exception reporting in the quality and outcomes framework. ${ }^{5}$

Our results indicate that identification of patients using the diagnostic case definition for the quality and outcomes framework (C10E and C10F hierarchy Read codes) artificially decreases the observed prevalence of diabetes, as observed by others. ${ }^{9}$ Although standardised coding has increased over time, we observed substantial variation in the use of Read codes across practices. For example, in 2007 the median proportion of people within a practice with type 2 diabetes who had a $\mathrm{C} 10 \mathrm{~F}$ code was $72.1 \%$ (interquartile range 67.1 $79.3 \%$ ). Only three practices had over $90 \%$ of people meeting the type 2 case definition of the quality and outcomes framework and four practices had less than $20 \%$ of people defined in this manner. In 2007 nearly two thirds of people with type 1 diabetes and a third of people with type 2 diabetes would not be identified using the diagnostic case definition in the quality and outcomes framework. Other studies have also reported similar underestimates of prevalence when only specific diabetes codes are considered. ${ }^{9}$ Further stan dardisation of coding is required if quality of care is to be monitored in an unbiased and effective way. ${ }^{6}$ This may require widespread education within primary care before the introduction of new indicators.

\section{Strengths and limitations of the study}

The mean prevalence in our study based on the quality and outcomes framework case definition $(2.7 \%$, range $0.2-5.1 \%$ ) was lower than reported nationally by Department of Health systems (3.7\%, range 0.0$14.4 \%),{ }^{25}$ although over $90 \%$ of practices included in the quality and outcomes framework reported a prevalence within our observed range. This may in part reflect the under-representation of practices in deprived areas, which tend to have higher proportions of people from ethnic minority groups and hence diabetes, in the database used in this study. ${ }^{26-28}$ The practices included in the (DIN)-LINK database have a similar age-sex structure to that of the UK population but have been shown to over-represent practices in the south of England and higher socioeconomic groups. ${ }^{15}$ In addition the practices included in this study (just under $50 \%$ of those contributing to the DIN-LINK database) were selected because they had high quality data available over a 10 year period, which allowed us to identify and assess the management of patients over time. These selected practices were spread throughout Great Britain but included a relatively high proportion of dispensing practices. We may anticipate that such practices with capture of higher quality data provide a different level of care, possibly higher, than those that do not meet such criteria. Furthermore, ease of accessibility to dispensing services may mean that some patients seen in our practices might have increased uptake and possibly compliance with therapy.

The prevalence of type 1 diabetes may be viewed as decreasing marginally over time, which could result from more accurate coding in general practitioners' notes, particularly in the case of people with type 2 


\section{WHAT IS ALREADY KNOWN ON THIS TOPIC}

Since the introduction of the quality and outcomes framework in the United Kingdom, a series of studies has suggested an improvement in the management of people with diabetes in primary care

It remains unclear to what extent the introduction of incentives has had an impact on existing temporal trends

\section{WHAT THIS STUDY ADDS}

Significant improvements in diabetes care were observed from 2002-7, although this does not seem to be a direct result of the quality and outcomes framework

Many people in whom care may be suboptimal do not seem to be captured in the quality and outcomes framework assessment owing to the current diagnostic case definition

diabetes treated with insulin being more accurately coded as such.

Our sensitivity analyses on patients who had $\mathrm{C} 10 \mathrm{E}$ and $\mathrm{C} 10 \mathrm{~F}$ Read codes and met the current case definition for the quality and outcomes framework was based on identification of these Read codes in the study period. Some people with earlier recorded morbidity Read codes may have been missed, but it is standard practice to include a Read code in the electronic record each time a patient is seen. Although the inclusion of people without $\mathrm{C} 10$ or the more specific $\mathrm{C} 10 \mathrm{E}$ and $\mathrm{C} 10 \mathrm{~F}$ codes in the analysis might be criticised, other Read codes were more commonly in use in the period before April 2006. Other studies have also used codes such as the diabetes care codes (66A) and prescription information to identify patient cohorts ${ }^{29}$ and have noted the inconsistent use of diabetes specific Read codes. ${ }^{6}$ As we aimed to assess the management of people with diabetes over time and the impact of the quality and outcomes framework, it was important to avoid spurious trends as a result of changes in diagnostic case definition. ${ }^{9}$ We also included people with codes for exception reporting ( $9 \mathrm{~h} 4$ codes) as these codes were not in use before April 2005 and so their use would have led to an inaccurate assessment of change in care over the study period. A more inclusive approach considering the entire population of people with diabetes provides a clearer picture of care both before and after the implementation of the quality and outcomes framework.

\section{Conclusions}

The management of people with diabetes in the UK has improved since the late 1990s. The relation between incentives and attainment of targets may not, however, be as straightforward as initial reports suggest. Pay for performance may have contributed to the improvement in diabetes care but the relative importance of the quality and outcomes framework to other national quality improvement strategies is unclear. Our work and that of others highlights the potential unintended consequences of the scheme, which include selective inclusion of patients in the scheme through the removal ${ }^{30}$ or addition of Read codes, exclusion of patients through exception reporting, ${ }^{22}$ and potential threshold effects, all of which require further evaluation. The scheme in its present form fails to capture almost one third of people in whom care may be suboptimal and may even lead to reduced levels of care for some groups of patients.

Contributors: MJC, AS, and NF conceived the study and did the data analyses. HL and RJM contributed to the design and analysis plan. MJC and AS wrote the first draft of the paper. All authors contributed to writing the manuscript and approved the final version. MJC is the guarantor. Funding: This study was sponsored by Pfizer. Analyses and interpretation were done independently of the sponsor. RJM was supported by a national primary care postdoctoral award 2005-7.

Competing interests: MJC, AS, RJM, and NF have received funding for research, consulting, and travel from several companies that manufacture therapies for diabetes.

Ethical approval: This study went through our formal institutional review process and it was agreed that no further ethical review was required.

1 Institute of Medicine. Rewarding provider performance: aligning incentives in Medicare. Washington: National Academies Press, 2007.

2 Roland M. Linking physician pay to quality of care: a major experiment in the United Kingdom. N Engl J Med 2004;351:1448-54.

3 Royal College Of General Practitioners. The GMS contract (overview and resources guide). London 2007. www.rcgp.org.uk/pdf/ ISS INFO GMS07.pdf.

4 British Medical Association 2009. www.bma.org.uk/ employmentandcontracts/independent_contractors/ quality outcomes framework/focusqoffeb06.jsp.

5 Doran T, Fullwood C, Reeves D, Gravelle H, Roland M. Exclusion of patients from pay-for-performance targets by English physicians. $N$ Engl/ Med 2008;359:274-84.

6 Gray J, Orr D, Majeed A. Use of Read codes in diabetes management in a south London primary care group: implications for establishing disease registers. BMJ 2003;326:1130.

7 Scottish Clinical Information Management in Practice. Making IT work for you: READ codes. 2009. www.scimp.scot.nhs.uk/gpg/ doc_page67.shtml.

8 Hippisley-Cox J, O'Hanlon S. Identifying patients with diabetes in the QOF-two steps forward one step back. BMJ 2006;333:672.

9 Hippisley-Cox J, Vinogradova Y, Coupland C. Final report for the information centre for health and social care: time series analysis for 2001-2006 for selected clinical indicators from the quality and outcomes framework. 2007. www.qresearch.org/ Public_Documents/Time\%20Series\%20Analysis\%20for\% 20selected\%20clinical.pdf.

10 Campbell S, Reeves D, Kontopantelis E, Middleton E, Sibbald B, Roland M. Quality of primary care in England with the introduction of pay for performance. N Engl J Med 2007;357:181-90.

11 Millett C, Gray J, Saxena S, Netuveli G, Khunti K, Majeed A. Ethnic disparities in diabetes management and pay-for-performance in the UK: the Wandsworth prospective diabetes study. PLoS Med 2007;4:e191.

12 Tahrani AA, McCarthy M, Godson J, Taylor S, Slater H, Capps N, et al. Diabetes care and the new GMS contract: the evidence for a whole county. Br J Gen Pract 2007;57:483-5.

13 Omnibus Survey System. 2008. www.icapp.nhs.uk/docdat/ DatabaseList.aspx.

14 ACORN geodemographic classification. 2008. www.caci.co.uk/ acorn/acornmap.asp.

15 Carey IM, Cook DG, De Wilde S, Bremner SA, Richards N, Caine S, et al. Developing a large electronic primary care database (doctors' independent network) for research. Int J Med Inform 2004;73:443-53.

16 Department of Health business rules. 2007. www. primarycarecontracting.nhs.uk/145.php.Version.No.11.0.

17 Harrell FE, Lee KL, Mark DB. Multivariable prognostic models: issues in developing models, evaluating assumptions and adequacy, and measuring and reducing errors. Stat Med 1996;15:361-87.

18 Harvey JN, Craney L, Kelly D. Estimation of the prevalence of diagnosed diabetes from primary care and secondary care source data: comparison of record linkage with capture-recapture analysis. J Epidemiol Community Health 2002;56:18-23.

19 UK Prospective Diabetes Study (UKPDS). Intensive blood-glucose control with sulphonylureas or insulin compared with conventional treatment and risk of complications in patients with type 2 diabetes (UKPDS 33). Lancet 1998;352:837-53.

20 Kerr E, Krein S, Vijan S, Hofer T, Hayward R. Avoiding pitfalls in chronic disease quality measurement: a case for the next generation of technical quality measures. Am J Manag Care 2001;7:1033-43.

21 Ashworth M, Seed P, Armstrong D, Durbaba S, Jones R. The relationship between social deprivation and the quality of primary 
care: a national survey using indicators from the UK quality and outcomes framework. Br J Gen Pract 2007;57:441-8.

22 Doran T, Fullwood C, Gravelle H, Reeves D, Kontopantelis E, Hiroeh U, et al. Pay-for-performance programs in family practices in the United Kingdom. N Engl J Med 2006;355:375-84.

23 Peyrot M, Rubin RR, Lauritzen T, Skovlund SE, Snoek FJ, Matthews DR, et al. Resistance to insulin therapy among patients and providers: results of the cross-national diabetes attitudes, wishes, and needs (DAWN) study. Diabetes Care 2005;28:2673-9.

24 Hippisley-Cox J, O’Hanlon S, Coupland C. Association of deprivation, ethnicity, and sex with quality indicators for diabetes: population based survey of 53000 patients in primary care. BMJ 2004;329:1267-9.

25 Information Centre for Health and Social Care. National QOF tables 2006-2007. Prevalence. 2008. www.ic.nhs.uk/statistics-anddata-collections/supporting-information/audits-and-performance/ the-quality-and-outcomes-framework/qof-2006/07/qof-2006-07data-tables.
26 Millett C, Car J, Eldred D, Khunti K, Mainous AG, III, Majeed A. Diabetes prevalence, process of care and outcomes in relation to practice size, caseload and deprivation: national cross-sectional study in primary care. J R Soc Med 2007;100:275-83.

27 Richard Dorsett, Joseph Rowntree Foundation. Ethnic minorities in the inner city. 2008. www.jrf.org.uk/sites/files/jrf/spr988.pdf.

28 Diabetes UK. Causes and risk factors. 2008. www.diabetes.org.uk/ Guide-to-diabetes/Introduction-to-diabetes/

Causes_and_Risk_Factors/.

29 Gray J, Millett C, Saxena S, Netuveli G, Khunti K, Majeed A. Ethnicity and quality of diabetes care in a health system with universal coverage: population-based cross-sectional survey in primary care. J Gen Intern Med 2007;22:1317-20.

30 Carey IM, DeWilde S, Harris T, Whincup PH, Cook DG. Spurious trends in coronary heart disease incidence: unintended consequences of the new GP contract? Br J Gen Pract 2007;57:486-9.

Accepted: 28 January 2009 